\title{
Diachronic Analysis of Florianópolis Urban Morphology and the Impact on Urban Mobility Related to Brasília
}

\author{
Caroline Machado da Silva ${ }^{1}$, Lucas Heiki Matsunaga ${ }^{2}$, Ingrid Luiza Neto ${ }^{3}$ and \\ Hartmut Günther ${ }^{1}$
}

\begin{abstract}
The diachronic analysis allows evaluating the evolutionary process of the cities and the diverse interconnections that constitute and qualify the main structuring networks using axial maps. This study aims to analyse the urban evolution, and the impact on urban mobility, of two Brazilian cities (Florianópolis and Brasília) using the Social Logic of Space Theory (SLST). Florianópolis is located on an island in the south of Brazil and Brasilia is located in the centre of the country,planned in the 1960 's to be the Brazil's capital. Both cities have a dispersed system of road networks, where the districts are separated from each other and by their form of implantation, being horizontal and dispersed. This causes the local population to take long daily commutes to reach the centralities of the cities, overloading the transport networks, either by the use of public transport or individual private transport. The strategy of analysis is applicable to the context of both Florianópolis and Brasilia, since it has the possibility of identifying the local and global centralities, more accessible routes and better options for spatial syntax based on the SLST. Also, it subsidies the identification of the intervention points and the promotion of more sustainable transport systems.
\end{abstract}

Keywords: Urban mobility, Florianópolis, Brasilia, Theory of Social Logic of Space, Sustainability, Axial maps

\section{Introduction}

The Social Logic of Space Theory (SLST) investigates the relationship between built environment and society as a system composed of interdependent structures. Therefore, when it is modified, it alters the whole system. The syntactic space analysis performs the recognition of the spaces from permeability and barriers, defining (in)accessible areas to a certain type of movement. It may be pedestrians, road vehicles, railways or waterways. In this study, we mainly analyzed the movements of road vehicles, using private areas or buildings as barriers and the streets and paths as permeable areas (Medeiros, 2006). In addition, the diachronic analysis of an urban spot allows observing the evolutionary process of the cities and the different interconnections that constitute and qualify their main structuring networks (Holanda, 2003).

\footnotetext{
| ${ }^{1}$ Universidade de Brasília - UnB

2Tohoku University

${ }^{3}$ Centro Universitário do Distrito Federal - UDF
} 


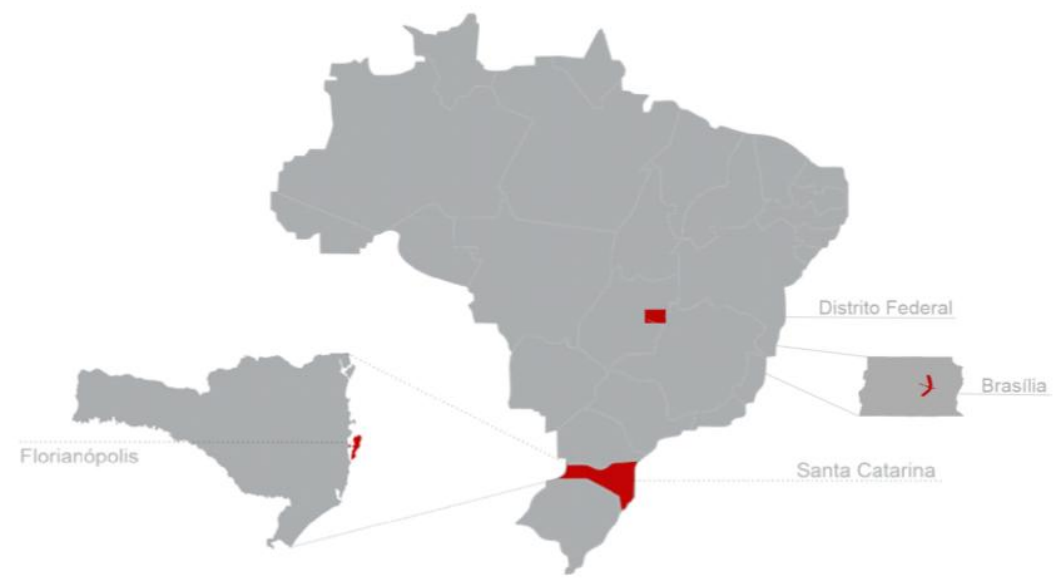

Figure 1: Map of Brazil with the location of Florianópolis and Brasilia. Source: Authors.

In this study, we analyse the urban evolution of the city of Florianópolis, capital of Santa Catarina, located in the South of Brazil and Brasilia, in the centre of Brazil (Figure 1). Also, we verify the impact of the urban design on the system of transports of each city. The choice of the cities was due to the authors' involvement with a larger study that investigated issues related to healthy urban mobility through environmental, psychological and demographic variables. The Brazilian cities studied were Brasilia, Florianópolis and Porto Alegre, through the Healthy Urban Mobility research project. However, only Brasilia and Florianópolis were analyzed in this study, because both cities have similar syntactic characteristics (Medeiros, 2006).

In general, Brazilian cities have different urban design characteristics. The cities of Brasília and Florianópolis suffer from these differences, the fact that Florianópolis is a mountainous island delimits relatively the urbanized areas. In Brasília, relief does not affect urbanization sites, although it has several areas of environmental preservation in the city. However, in both cities, there are characteristics of scattered cities. Thus they share low connectivity among the road system and have a predominant non-sustainable transport system.

\subsection{Florianópolis' Urban Context}

In this section, we analysed the configurational and morphological aspects of Florianópolis mesh from 1819 to 2018, using syntactic analysis. The aim is to indicate the changes from its initial urban configuration as a village until its current configuration as a metropolis within the scope of urban mobility. The first inhabitants of the Island, where the city of Florianópolis is located, were the Tupi-Guarani indigenous that with the arrival of the Portuguese empire, soon began to disappear or became slaves by those (Bastos, 2004). In the century XVII, a man from São Paulo, a city in Brazil, had the mission to populate the captaincy, following the model of the Portuguese empire expansion. With his death in 1689, it generated decadence in the population growth.. The eighteenth century was marked mostly as a period of scarcity on this place. Until in 1726, when the village was elevated to the category of town, titled as Vila de Nossa Senhora do Desterro (Bastos, 2004). 
Besides that, the Spanish Dom Pedro Cerralhos landed on the island with his family and an army of twelve thousand men. So, at the end, the Island became a Spanish territory for a while (Araújo, 1989). In the nineteenth century, Jerônimo Coelho inaugurates the first newspaper, the first public library, the first public market and first the street. In 1837, the city's streets received the first public lighting system, subsidized with lanterns. (Dall'alba, 1983). At the beginning of the XX century, Florianópolis had a slow growth and the economy was based only on a small commerce and a public administration. From 1920, the city began to breath modern air, with the movement of appreciation of nature, when the population started using the beaches. Thus, the sea bath became more frequent for those. This made its inhabitants explore even more the other regions on the island and began the process of urban expansion to the interior of the island. The construction of the bridge Hercilio Luz created a strong physical link between the island and the continent. The car fleet growed up significantly since there was the possibility of moving from the island to the mainland. With the increase of the population and of the automobile use, there was a need to create new bridges and landfill. In consequence, the setting of the historic centre was changed, because of its distance from the sea (Figure 2) (Araújo, 1989).
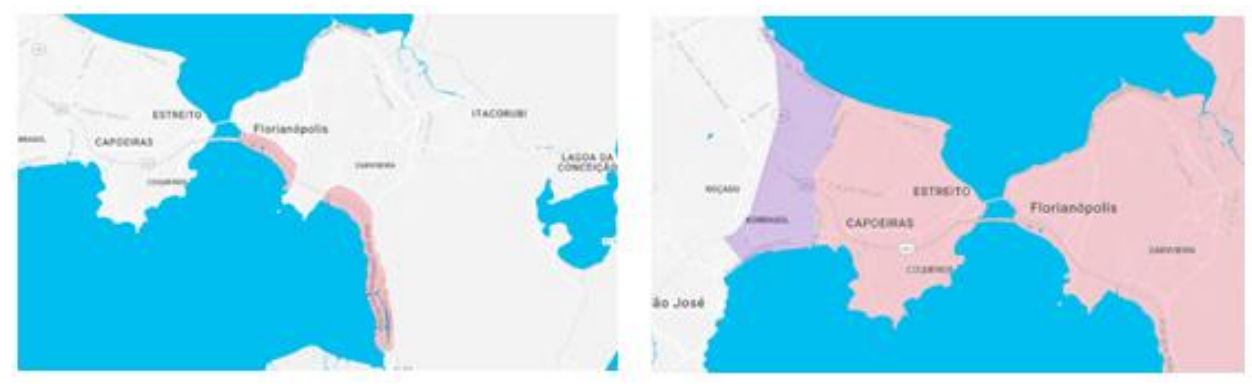

Figure 2: Image of the left indicates, in red, the landfill area implanted in the second half of the twentieth century. Image of the right indicates the area of the municipality of Florianópolis, in red, and the area of the municipality of São José that will be analysed in this work, in purple. Source: Google maps with changes made by the authors.

A large number of demolitions in the city marked the 1970s. The densification and verticalization policies in the city centre have become increasingly common. However, this occurred without concern for the preservation of historic landmarks that were part of urban life (Veiga, 1993). Currently, Florianópolis is a synonymous of quality of life, with a human development index of 0.847 , ranging from 0 to 1 , occupying the third position in Brazil. The city has almost 500 thousand inhabitants, in an area of 440 square kilometres. The life expectancy at birth is more than 77 years. In addition, it has good indicators of health and education (IBGE, 2010). The city has a characteristic of occupation in plains and valleys and owns a great area destined to environmental preservation.

\subsection{Brasília's Urban Context}

Brasilia is located in the centre of the country, in the Federal District. In 1955, the president decided to build the new capital of Brazil in the centre of the country. The 
proposal of Lúcio Costa won the urban project contest and from a region hitherto uninhabited emerged the current Brazilian capital. The project was based on the premises of modern urbanism and the Charter of Athens (1933), with two main axes structuring the city, which divides it into several sectors. The capital was inaugurated in 1960 and suffered heavy immigration from people from all over the country. The Federal District (FD) currently consists of thirty-one Administrative Regions (ARs), totalling 2,570,160 inhabitants in the completely metropolitan region. The region's Human Development Index is 0.824, one of the highest in Brazil (IBGE, 2010). The territory is organized according to its economic activities, having a central attractive pole that generates a daily pendular movement. Although this region gradually decreases the concentration of services and commerce, it still covers $46.33 \%$ of the FD.

The other ARs informally called "satellite cities", have characteristics of dormitory cities, where commuting is frequent at the beginning and end of the day. Most of the ARs are located at a considerable distance from the Plano Piloto (Ojima et al., 2010). This distance leads to long journeys by residents, which are often dangerous and unfriendly for people walking or cycling. In addition, public transport on rails does not cover the whole FD and the bus system has high costs, is oversized and absent (Paviani, 1987).

Considering the urban morphology, some neighbourhoods in Brasília were built under pilotis, with up to six floors for residential use, medium population density, existence of local commerce next to the buildings, a hierarchical system of roads with well-structured and high afforestation rates, when compared to other ARs in the FD. These, in turn, are mostly the result of a horizontal city occupation morphology. Although some of them have been planned, they have large empty areas, lack of afforestation, urban infrastructure, pavement, and accessibility. Sometimes they do not even have a high school, or a clinical centre (Paviani, 1987). With this, residents need to travel long distances to access commercial areas and services in general, constituting an urban environment that may not encourage citizens to walk (Southworth, 2005).

Thus, the FD followed an urban model of peripheral expansion, marked by social inequalities. Some of the population was "driven out" from the most central areas of the city, living on the periphery and using the central areas for occupational purposes. This peripheral movement generates the need to expand the transportation system, so that it can meet the daily needs of the population displacement (Ghidini, 2010).

\section{Method}

\subsection{The object}

The study uses axial maps of the city of Florianópolis, based on linear representations of the road system, where the lines represent possible and direct paths within the urban fabric (Medeiros, 2006). The values of the syntactic variables of Brasilia were also used. Based on satellite imagery of Google Maps using the hybrid maps and streets, only those indicated by these maps were considered. Since the vegetation presented in the place did not leave the paths visible for the production of the map, the analysed area chosen was delimited just to the Island, going slightly from beyond the boundary of the municipality to the Governador Mário Covas Highway (Figure 2).

It had a border characteristic in the region, since it is a central highway in relation to the 
Metropolitan Region of Florianópolis, with great impact for the region. The fact that the districts of the municipality of São José that border Florianópolis integrate with the urban network of the capital, it is relevant to carry out the analysis also of this area. In order to compare the data of the city of Brasilia, it was considered the data presented in the book Urbis Brasiliae (Medeiros, 2013).

\subsection{Cartographic Bases and Representations of Axial Maps}

From the elaboration of the axial map of the city, it was possible to analyse the potential movement according to the urban configuration. The maps of the diachronic analysis were developed from the cartographic base provided by the Institute of Urban Planning of Florianópolis (IPUF). After contacting its servers via e-mail and telephone, they provided ancient digitized maps of the years 1819, 1876 and 1916. The maps of Florianópolis found and provided by IPUF prior to 1819 do not represent in a reliable way the urban form, but do represent the territory, the natural and geographical aspects of the Island, justifying the time frame assigned to the study. The most recent diachronic analysis was carried out based on the mosaics of high-resolution satellite images of the years 1938, 1957, 1977, 1994 and 2002. The analysed map for the year 2018 was based on satellite images provided by Google, through the QuickMapServices plug-in. All values of the Brasilia variables refer to the year of 2018 .

\subsection{Data processing and analysis}

The lines were drawn using QGis software version 2.18.11. Maps were processed using Depthmap software version X, 035, with the aid of the Space Syntax Toolkit plug-in. The variables analyzed were only those that met the objectives of the study.,including system area, number of axes, average length of axes, number of axes per $\mathrm{km}^{2}$, length of axes per $\mathrm{km}^{2}$, global integration, normalized integration (NAIN) and normalized choice $(\mathrm{NACH})$. After the maps were processed, the values of each of the variables were obtained and several graphs were processed using Microsoft Office Excel software version 2016.

\section{Results}

The variables evaluated in the study have two distinct natures: a) geometric nature, which present formal characteristics; and b) topological nature, that has characteristics related to the system. In eight variables, they will be used to analyse the relations between the elements of urban space under the perspective of the social logic of space.

\subsection{System Area}

Figure 3 shows that Florianópolis had an urban occupation mainly in the historical centre. The expansion of the urban mesh happened in the 1920s, when the population began to explore the beaches, taking it as an area of leisure and cultural conviviality. It is clearly observed the growth of the urban spot, mainly from the decade of 1950, a moment where the whole country suffered from the increase of urbanization. The area of the system increases according to the expansion of the city, having a strong 
relationship with the rugged relief. However, urban growth did not imply the occupation of the hills, only the areas of valleys and plains. In the twentieth century, unpopulated hill areas mainly became areas of environmental preservation, which explains the irregularity in the urban areas consolidated in the most recent map (see Figure 10).

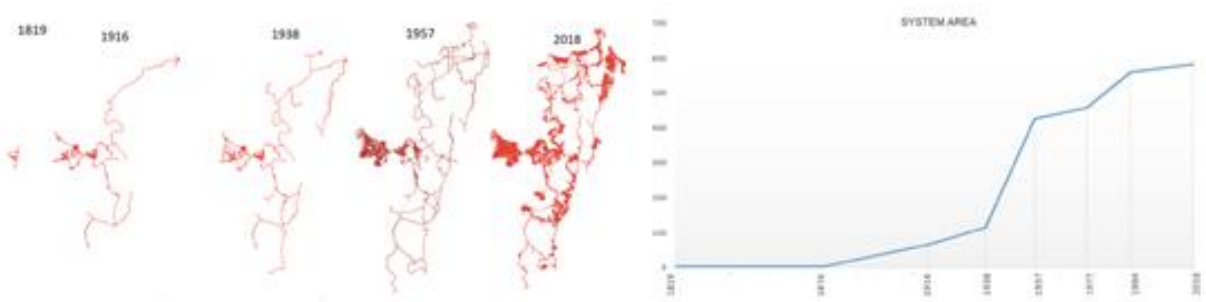

Figure 3: Image of axial axle systems for each historical moment. Area chart of the axial axes systems in $\mathrm{km}^{2}$ in different periods. Source: Authors.

Figure 3 shows an increase in urban occupation in Florianópolis over time. However, the area of the system between $1938(115.6 \mathrm{~km})$ and $1957\left(427.5 \mathrm{~km}^{2}\right)$ increased significantly, due to the complete exploration of practically the whole island. In the present time, the urban area of the island of Florianópolis occupies around $600 \mathrm{~km}^{2}$, similar to Brasilia, which has $511 \mathrm{~km}^{2}$. Thus, the size of the system of the analysed areas have similar scales, disregarding the metropolitan region.

\subsection{Number of axles and Average length of axles $(\mathrm{km})$}

The number of lines in the diachronic analysis of the axial maps of each of the systems has increased in the various historical periods. In the second half of the twentieth century there was an evident increase in the number of axes of the systems and between 1938 (1472 axes) and 1957 (3591 axles) the number of axes increased from double axes (Figure 4). Here was also a marked increase in the number of lines of the system, representing a system of great size and complexity, surpassing in 2018 ten thousand axial axes, without consider the metropolitan region of Florianópolis.

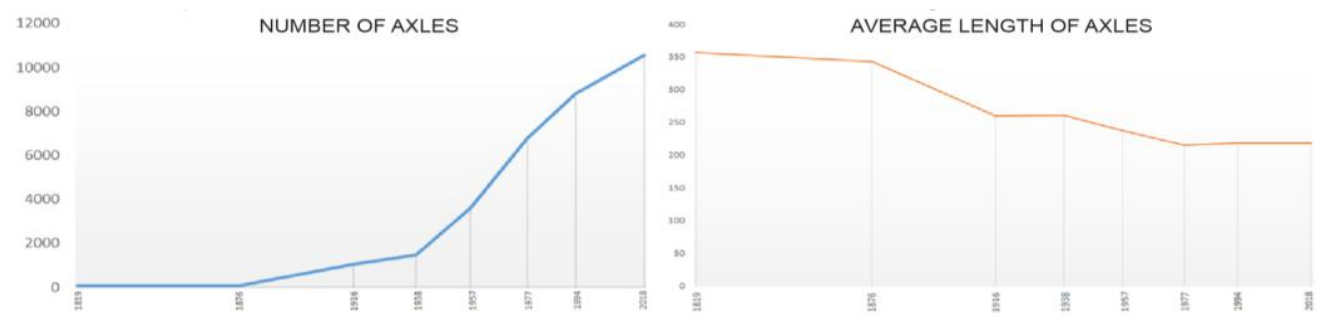

Figure 4: Graph of the absolute number of the axial axes and the average length of the axes in different periods. Source: Authors.

Over the decades, a decrease in the average length of the axial axes of the systems has been observed. Due to the low number of lines at the beginning of the consolidation of the village, and its small area occupied, a larger average length of axes was obtained. In 
addition, it can be observed that from the 20th century the expansion took place more organically due to the local topography, increasing the number of smaller axes and reducing the average size of the axes. The system of Brasília has 3,706 lines, which is equivalent to almost a quarter of the number of axes when compared to the Florianópolis system. However, the average length of the axles in Brasilia reaches 500 meters, almost double the average length of the axes in Florianópolis. This can be explained by the irregularity of the road system in Florianópolis and its mountainous topography, which does not occur in Brasília.

\subsection{Number of axles per $\mathrm{km}^{2}$ and length of axles per $\mathrm{km}^{2}$}

This variable measures how the stain is dispersed or compacted. In the first two moments evaluated in this study, it was noticed an increase in the average value of axes per $\mathrm{km}^{2}$ since the occupation of urban voids in the area of the historical centre without a significant increase of the area. The times from 1916 to 1957 were marked by a reduction of this value, considering that during this period, the population began to occupy areas farther from the centre, significantly increasing the area of the urban spot. From 1957, the average value of axles per $\mathrm{km}^{2}$ increased, due to the fact that the occupation area slightly enlarged. In this frame, the population began to occupy the urban voids present on the island, consequently increasing the number of axes. Nevertheless, all the values of this variable for Florianópolis were quite below the national average ( 94.8 axles $/ \mathrm{km}^{2}$ ), a due to a large number of environmental preservation areas in the city, mainly in hilly areas.

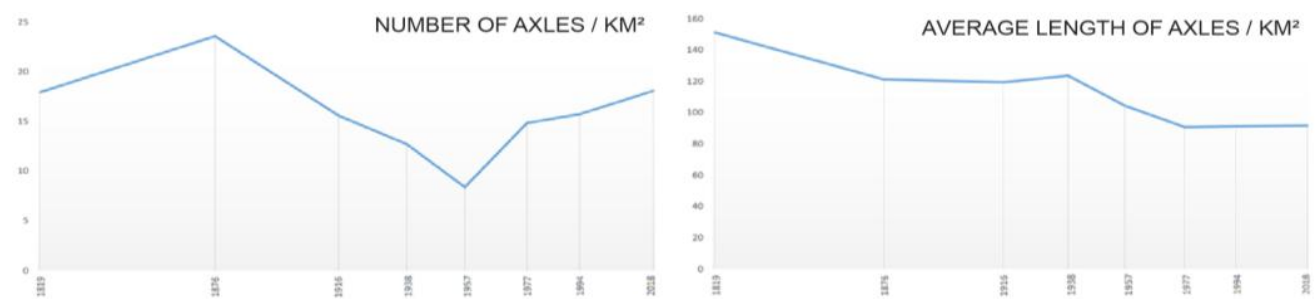

Figure 5: Graph of the number of axes per $\mathrm{km}^{2}$ and length of axles per $\mathrm{km}^{2}$ in different periods. Source: Authors.

When comparing the length of axes per $\mathrm{km}^{2}$ with the numbers of axles per $\mathrm{km}^{2}$, similar behaviour of the line is observed. There is an increase in the first two moments and a decrease from 1876 to 1957, followed by an increase in the value of the length average per $\mathrm{km}^{2}$ (Figure 5). These values are below the value of the national average for compacity B, mainly due to the type of occupation present in Florianópolis. The value of compactness A for Brasília is 7.25 axes $/ \mathrm{km}^{2}$, and the compactness B of this system has a value of 97.8 , very similar to that of Florianópolis.

\subsection{Global Integration}

The overall integration of the system indicates some characteristics of the urban layout's centrality. It is important to gauge the arrangement of the most integrated set of axes, considered as a redder chromatic band in the map of global integration, called integration core. Because accessible areas concentrate more uses of trade and services, 
the nucleus of global integration generally coincide with the urban centre of cities (Barros \& Medeiros, 2014). Therefore, an area with a higher integration value is the more permeable and accessible potential area, which is easier to reach (Medeiros, 2006).

Figure 6 presents the results of global integration. It can be observed in the case of Florianópolis that the core of global integration remained in the same place over time, even if there is a difference in the values of the average global integration in the historical moments analysed. More once, higher indexes were observed in the first two historical moments due to the compact occupation of the urban network. This was followed by a decrease in the average values due to the spreading of the urban spot in a discontinuous way, mainly due to its irregular relief. It should be noted that Florianópolis remained below the national average of 0.76 , at different moments of analysis. Brasilia has a global integration value of 0.656 , significantly different from the value found in Florianópolis, 0.199. This is explained by the presence of a large environmental preservation area in the centre of the island, which hinders the integration of the road network as a whole.
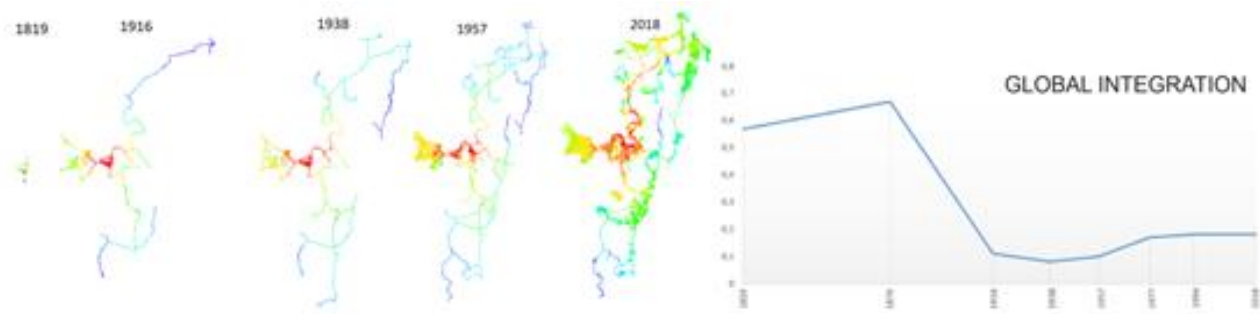

Figure 6: Image of the global integration analysis of the axial axis systems for each historical moment. Graph of the systems' global integration in different periods. Source: Authors.

\subsection{NAIN (normalized integration)}

Normalized integration verifies the accessibility potential of the pathways with the normalized calculation as to the size of the system, which allows the comparison among systems of different dimensions. Figure 7 shows the centrality of the site, so that the smallest angular path coincides with the integration centre of each of the systems. It is observed a peak in the year 1957, when there was an increase in the area of the system and its occupation.

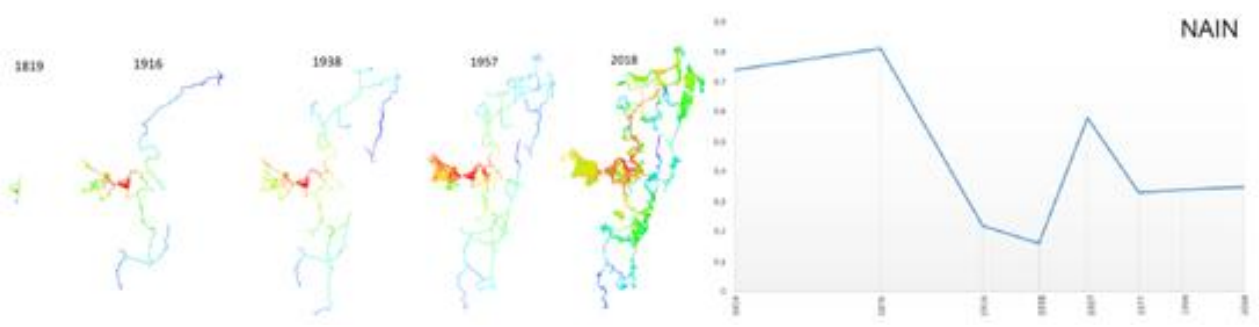

Figure 7: Image of the analysis of normalized integration of the systems of axial axes referring to each historical moment. NAIN analysis chart of systems in different periods. Source: Authors. 


\subsection{NACH (normalized choice)}

Normalized choice verifies the potential of a particular path or a set of ways to compose the most commonly used path network for the entire system. It allows comparison between systems of different sizes. Figure 8 shows the main paths in the system network, coinciding with the existing road hierarchy in the city. The roads in red intersect with the main avenues of neighbourhoods' connection. In the first two analysed moments of the graph, the values were much higher than the later moments, which occurs by the small area of urban occupation. Up to 1957, there was a decline in the $\mathrm{NACH}$ values, due to urban sprawl. After this date, this value stabilized.

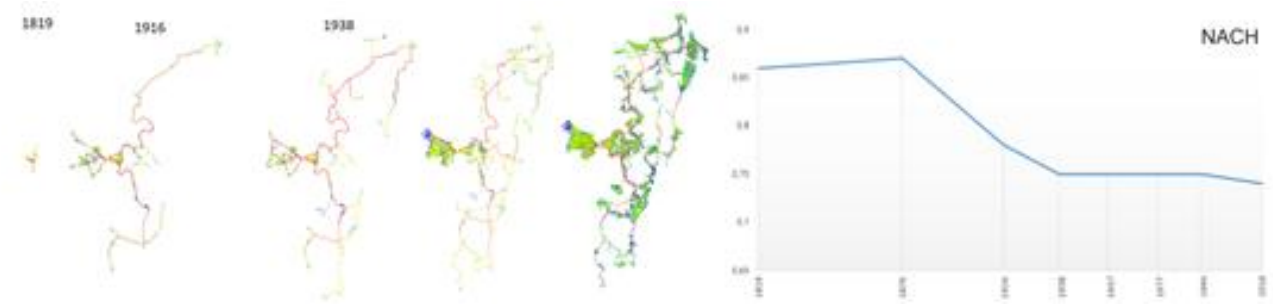

Figure 8: Image of the analysis of normalized choice of systems of axial axes referring to each historical moment. NAIN analysis chart of systems in different periods. Source: Authors.

In the city of Brasilia, the growth and expansion of the urban area happened at the end of the XX century and at the beginning of the XXI century (Figure 9). It is important to mention that it is a recent city, inaugurated in 1960.
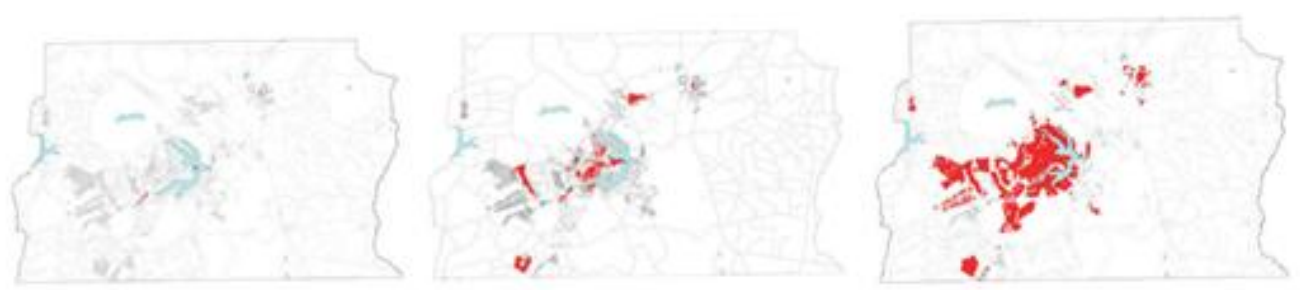

Figure 9: Images of the urban spot of the Federal District in 1958, 1954 and 1991, respectively. Source: Governo do Distrito Federal, 2015

\section{Conclusions}

In Florianópolis, it is possible to observe a growth of the system in all the analysed periods. The first historical moment analysed was marked by a compact occupation in a small area, higher values of NACH, NAIN, global integration and compactness.

In the second half of the twentieth century, there was a large increase in the area of the system and in the number of axes and segments, due to the growth of the urban occupation patch and the population increase of the municipality. The analyses related to these magnitudes had a similar behaviour as observed in the graphs of figures 3 and 4 . Associated with this, there is the exploration of the more peripheral areas of the city with the movement of nature valorisation and the increase of the fleet of automobiles that 
facilitated the displacement.

In particular, the period of 1957 was atypical, with increased values of synergy, NAIN, intelligibility and decreased values of compactness. Due to the increase in the area of the system that went from $115 \mathrm{~km}^{2}$ to $428 \mathrm{~km}^{2}$, this jump in the system area significantly altered these variables, being associated with a population and a fleet increase.

From the '60s, the variables stabilized, since the border of the island portion was almost all occupied. The growth vector was changed to the continental region of the municipality. It is important to emphasize that the city is below the national average values for average lengths of the axes, connectivity, global and local integration, intelligibility and synergy. The fact that the city was occupied mainly in valleys and plains areas, and its relief, affected the format of implantation, generating more discontinuous and organic paths.

The city has a well-developed and vertical central area, where the core of global integration coincides with, yet the values below the national average can be explained by the high amount of environmental preservation areas, in hilly areas and in the city within the urban perimeter. As the metropolitan region was not analysed in this study, the analysis of São José and Biguaçu would possibly raise these values. In the XXI century, it was possible to observe an increase in the occupation in areas of urban voids, mainly in the North area of the island, and in areas near the beach. There was little change in the polygon of the integration core and maintenance of global and local integration values. In the city of Brasilia, there was a movement similar to that seen in Florianópolis where there was an occupation and a expansion of the urban areas in the same period at the end of the XX century and at the beginning of the XXI century. However, in Florianópolis the urban expansion was mainly towards the continent, since the island has restricted space and also a relevant area destined to green areas for environmental preservation. What is noticeable is that the use of private motorized transport is part of the daily life of the residents in both regions, associated with precarious, high tariff and low-quality public transport. Thus, the population is encouraged to use the car, generating an overload in the system by city roads.

The diachronic indicated that the process of urbanization of the both cities analyzed occurred in the central region and then in poles far from the centre. This process generated the need to create a connected structure of routes among these points. However, the permanent demand of the inhabitants in realizing their daily movements from the periphery to the centre overloaded these routes. Both cities are characterized by having distant poles around them, which causes a need to make longer journeys within the urban perimeter with isolated and almost unique routes that connect one centre to another.

It is clear that this type of system was not thought to have a sustainability of its own, where a mode of transport can subsidize others and balance the system. On the contrary, what is observed are commuting movements of people and automobiles that leave the peripheries to the central regions to develop their activities. Then, the centres of the cities overloads with thousands of vehicles. Something similar happens with the public transport system, where it is possible to see an overload in a sense of flow from the peripheries to the centre and in the counterflow the vehicles come back empty, not generating tariffs to compensate this transport system. 
Besides the overload of the systems and the accumulation of private cars clogging the urban centres, it is necessary to rethink the cities as a whole, including reviewing the points of centralities and points attracting people. Once this is implanted in urban design, it is possible that the mesh metropolitan urbanization has several centralities. Thus, the overhead in specific routes at peak times become more sparsely dispersed, with an urban design that encourages the movements of all parts to all parts of the city avoidance of an overload in both the roads and in transport systems. In that way, economic sustainability for the public transport systems is maintained, so that people are in and out of the transportation system both in the flow and in the counterflow, improving the quality of transport services.

\section{References}

Araújo, H. R. D. (1989). A invenção do litoral: reformas urbanas e reajustamento social em Florianópolis na Primeira República.

Barros, A. P. B. G., \& Medeiros, V. A. (2014). Centralidades e Sintaxe Espacial: variáveis para a compreensão da acessibilidade urbana. Projecto e Cidade: Centralidades e Mobilidade Urbana. Universidade Federal de Goiás: Goiânia.

Bastos, M. D. D. D. A. (2004). Atlas do Município de Florianópolis. Florianópolis: IPUF.

Veiga, E. V. D. (1993). Florianópolis memória Urbana. 1ª edição. Florianópolis: Editora UFSC

Dall'Alba, J. L. (1983). Imigração italiana em Santa Catarina: documentário. Florianópolis: Editora da Universidade de Caxias do Sul, 1983.

Holanda, F. B. R. (2003). Arquitetura e urbanidade. Brasília: PróEditores.

Ghidini, R. (2010). A caminhabilidade: Medida urbana sustentável. Disponível em: http://www.mobilize.org.br/midias/pesquisas/a-caminhabilidade-medida-urbana-sustentavel.pdf. Acesso em 08/07/2017.

IBGE (2010). Censo 2010. Disponível em wmw. ibge. gov. br/censo 2010. Acesso em 08/06/2017.

Medeiros, V. A. S. D. (2006). Urbis Brasiliae ou sobre cidades do Brasil: inserindo assentamentos urbanos do país em investigações configuracionais comparativas.

Medeiros, V. (2013). Urbis Brasiliae: o labirinto das cidades brasileiras. Editora UnB. Brasília: Editora da Universidade de Brasilia.

Ojima, R., Marandola J. E., Pereira, R. H. M., \& da Silva, R. B. (2010). O estigma de morar longe da cidade: repensando o consenso sobre as "cidades-dormitório" no Brasil. Cadernos Metrópole., 12(24).

Paviani, A. (1987). Urbanização e metropolização: a gestão dos conflitos em Brasília. Brasília: Editora Universidade de Brasilia.

Southworth, M. (2005). Designing the walkable city. Journal of urban planning and development, 131(4), 246-257. 